\title{
Effects of green tea, black tea and Rooibos tea on angiotensin- converting enzyme and nitric oxide in healthy volunteers
}

\author{
Ingrid A-L Persson $1, *$, Karin Persson ${ }^{1}$, Staffan Hägg ${ }^{2}$ and Rolf GG Andersson ${ }^{1}$ \\ 'Department of Medical and Health Sciences, Division of Drug Research/Pharmacology, Faculty of Health \\ Sciences, Linköping University, SE-581 85 Linköping, Sweden: ${ }^{2}$ Department of Medical and Health Sciences, \\ Division of Drug Research/Clinical Pharmacology, Faculty of Health Sciences, Linköping University, \\ Linköping, Sweden
}

Submitted 19 May 2009: Accepted 5 January 2010: First published online 10 February 2010

\begin{abstract}
Objective: Tea has been reported to reduce cardiovascular mortality, but the underlying mechanisms are largely unknown. The aim of the current project was to investigate the effect of green tea (Japanese Sencha), black tea (Indian Assam B.O.P.) and Rooibos tea (South Africa) on angiotensin-converting enzyme (ACE) and nitric oxide (NO).

Design: Seventeen healthy volunteers received a single oral dose of $400 \mathrm{ml}$ green tea, black tea or Rooibos tea in a randomized, three-phase, crossover study. ACE activity and NO concentration were measured (at 0, 30, 60 and $180 \mathrm{~min}$ ) in all phases. ACE activity was analysed by means of a commercial radioenzymatic assay. Nitrite was analysed as a marker of NO concentration. In addition, $A C E$ genotype was determined using a PCR method.

Results: Oral intake of a single dose of Rooibos tea significantly inhibited ACE activity after $30 \mathrm{~min}(P<0 \cdot 01)$ and after $60 \mathrm{~min}(P<0 \cdot 05)$. A significant inhibition of ACE activity was seen with green tea for the ACE II genotype $30 \mathrm{~min}$ after intake of the tea $(P<0 \cdot 05)$ and for the $A C E I D$ genotype $60 \mathrm{~min}$ after intake $(P<0 \cdot 05)$. A significant inhibition of ACE activity was also seen with Rooibos tea for the ACE II genotype 60 min after intake $(P<0 \cdot 05)$. No significant effect on NO concentration was seen. Conclusions: These results suggest that green tea and Rooibos tea may have cardiovascular effects through inhibition of ACE activity.
\end{abstract}

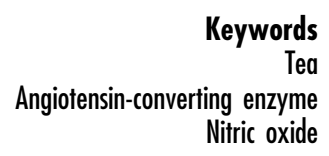

Green tea and black tea are derived from the leaves of Camellia sinensis L. (Theaceace). Green tea is produced by rapid heating of the leaves to preserve the colour and antioxidative compounds present in C. sinensis. Black tea is produced by a fermentation process, which is known to reduce the content of antioxidants ${ }^{(1)}$. Rooibos tea is produced from the leaves and stems of Aspalathus linearis Dahlg. (Leguminosae) and is a caffeine-free alternative to green and black tea. Tea is suggested to reduce mortality in $\mathrm{CVD}^{(2,3)}$, such as acute myocardial infarction ${ }^{(3)}$. Several positive effects of tea on the cardiovascular system have been shown: reduction of atherosclerosis ${ }^{(4)}$ and lipid peroxidation $^{(4-7)}$, anti-inflammatory properties ${ }^{(6,7)}$ and improvement of endothelial function ${ }^{(8)}$.

The effect of tea is suggested to be due to its high content of the flavonoid group catechins, i.e. epicatechin, epigallocatechin, epicatechingallate and epigallocatechingallate ${ }^{(9-11)}$. Epigallocatechingallate is the catechin most associated with the preventive effects of tea on CVD, due to its strong antioxidative properties ${ }^{(\vartheta, 10)}$. In contrast to green and black tea, Rooibos tea contains dihydrochalcones, flavones and flavonols ${ }^{(12)}$ but does not contain any catechins ${ }^{(11)}$.
Angiotensin-converting enzyme (ACE) is a key enzyme in the renin-angiotensin aldosterone system (RAAS). ACE converts the inactive decapeptide angiotensin I, forming the active octapeptide angiotensin II. Angiotensin II is a main effector of the RAAS and seems to be involved in developing CVD. Angiotensin II binds to the angiotensin receptors $\mathrm{AT}_{1}$ and $\mathrm{AT}_{2}$. Activation of $\mathrm{AT}_{1}$ receptors is associated with endothelial dysfunction ${ }^{(13)}$, vasoconstriction $^{(13)}$, cell proliferation ${ }^{(14)}$, platelet aggregation ${ }^{(15)}$, inhibition of nitric oxide synthase ${ }^{(16)}$, aldosterone release ${ }^{(17)}$, cognitive and behavioural processes such as depression, anxiety, enhanced learning and memory ${ }^{(18-20)}$, dementia ${ }^{(20)}$ and increases in reactive oxygen species ${ }^{(21)}$.

The $A C E$ gene polymorphic sites are an insertion/ deletion (I/D) consisting of three genotypes: $I I$ and $D D$ homozygotes and $I D$ heterozygote ${ }^{(22)}$. The I/D polymorphism of the $A C E$ gene determines individual serum levels of $\mathrm{ACE}^{(22,23)}$. The levels of $\mathrm{ACE}$ are two- to threefold higher in people with the $D D$ genotype than in those with the $I I$ genotype, and people with the $I D$ genotype have an intermediate level of $\mathrm{ACE}^{(22,24)}$. The $D$ allele of the ACE gene is proposed to correlate with $\mathrm{CVD}^{(25,26)}$. 
Hence, it seems that the $D D$ genotype could be a risk factor for $\mathrm{CVD}^{(24)}$.

There are several interactions known between the RAAS and nitric oxide (NO). Angiotensin II and NO act as physiological antagonists concerning vascular tone and growth $^{(27)}$. NO has also been proposed as a negative regulator of angiotensin receptors, and endothelial angiotensin receptors may stimulate $\mathrm{NO}$ release $\mathrm{e}^{(28)}$. Furthermore, activation of the RAAS is believed to be involved in tolerance to organic nitrates ${ }^{(29)}$. $\mathrm{NO}$ is proposed to act as an ACE inhibitor in rats ${ }^{(30)}$. It has also been shown that exogenous and endogenous NO can inhibit ACE in pigs and man in vitro and this NO-mediated ACE inhibition is additive with traditional ACE inhibitors like captopril, and of functional importance concerning angiotensin I-induced vasoconstriction and platelet aggregation ${ }^{(31,32)}$. This implies that NO not only has direct inhibitory effects on atherogenesis, but also indirect effects by decreasing the amount of angiotensin II.

In previous studies we found that green tea and black tea can inhibit ACE activity in human endothelial cells and that green tea, black tea and Rooibos tea can increase NO concentration from the same cells ${ }^{(11)}$. Since there are no in vivo data supporting these effects, we wished to study the effect of green tea, black tea and Rooibos tea on ACE activity and NO concentration in healthy volunteers in vivo.

\section{Materials and methods}

\section{Study subjects}

The study protocol was approved by the regional Ethics Committee at Linköping University, Sweden (Dnr M5607) and informed consent was obtained from the twenty non-nicotine-using healthy volunteers (ten males and ten females) who took part in the investigation. Their age ranged between 20 and 31 years with a mean value of 26 years. All subjects were healthy, as assessed by medical history and physical examination. Study participants did not use any kind of drugs (medical or herbal) two weeks prior to and during the entire sampling period. Intake of beverages or foods containing high amounts of catechins, the flavonol quercetin or anthocyanins (i.e. chokeberries, aubergine, blackberries, bilberries, elderberries, raspberries, strawberries, coffee, cacao/chocolate, cherries, onions, plums, pears, radishes, red and black currants, red cabbage, black beans, cranberries, tea, wine, grapes and apples) was not allowed $48 \mathrm{~h}$ before the experiment. A list of foods not allowed was distributed to the participants when they registered to the study. The participants also answered a questionnaire concerning everyday intake of certain foods, i.e. vegetables, fruits and berries, containing the flavonoids catechins, quercetin and anthocyanins. Three subjects were excluded (one male and two female); two because of practical difficulties when collecting blood and one due to oral use of tobacco.

\section{Study design}

A randomized three-phase crossover design was used and the phases were separated by a period of $1-4$ weeks. Forty-eight hours prior to each phase, the participants were not allowed intake of food or beverages containing high amounts of certain flavonoids (as mentioned above). The study subjects received $400 \mathrm{ml}$ of green tea (Japanese Sencha), black tea (Indian Assam B.O.P.) or Rooibos tea (South Africa) in each phase. All experiments started at 08.00 hours and the subjects were not fasting, to resemble ordinary intake of tea. The tea was freshly prepared and cooled so the participants could drink it within approximately $2 \mathrm{~min}$. The tea was prepared from green tea, Japanese Sencha imported by Charabang, Stockholm, Sweden; black tea, Indian Assam B.O.P. imported by Norrköping Kolonial, Sweden; and Rooibos tea imported by Norrköping Kolonial, Sweden. The teas were bought at Tebladet, Linköping, Sweden. Infusions were made with $10 \mathrm{~g}$ tea in $400 \mathrm{ml}$ fresh-boiled water for $5 \mathrm{~min}$ with the green tea and the black tea, and for $10 \mathrm{~min}$ with the Rooibos tea, using a tea filter (Agatha's Bester, Germany). The different boiling times were used to mimic the brewing of tea in households.

\section{Sample collection}

Data collected at each treatment were blood pressure, heart rate and venous blood samples for analyses of ACE activity, NO concentration and $A C E$ genotype. Blood pressure, heart rate and blood samples for analyses of ACE activity and $\mathrm{NO}$ concentration were taken before drinking tea and after $30 \mathrm{~min}, 60 \mathrm{~min}$ and $3 \mathrm{~h}$. Blood pressure and heart rate were measured in both supine and standing position, while blood samples were collected in supine position. Vacutainer tubes without anticoagulant were used to collect blood for serum-ACE and serum-nitrite analyses. After $2 \mathrm{~h}$, the tubes were centrifuged at $1000 \mathrm{~g}$ for $20 \mathrm{~min}$ at $4^{\circ} \mathrm{C}$. Serum was transferred to plastic tubes and ACE activity was analysed the same day, as described below. Remaining serum was frozen at $-70^{\circ} \mathrm{C}$ until nitrite analysis. Vacutainer tubes with EDTA were used to collect blood for determination of polymorphism concerning the $A C E$ genotype. The blood was transferred to sterile test tubes and frozen at $-70^{\circ} \mathrm{C}$ until analysis.

\section{Analytical methods}

ACE activity was analysed using a commercial radioenzymatic assay (ACE-direct REA; Bühlmann Laboratories, Allschwil, Switzerland) with the following modifications. Blank and standard serum and the human serum were added to wells in a microtitre plate. The synthetic substrate $\left[{ }^{3} \mathrm{H}\right]$ hippuryl-glycyl-glycine was then added directly to all wells. The serum was incubated for $1 \mathrm{~h}$ at $37^{\circ} \mathrm{C}$ to allow for the ACE present to cleave the substrate to $\left[{ }^{3} \mathrm{H}\right]$ hippuric acid. Then serum and substrate was transferred from each well into scintillation vials containing $50 \mu \mathrm{l} 1 \mathrm{~m}-\mathrm{HCl}$, to stop the enzymatic reaction. 
Scintillation liquid was added and the samples were counted in a scintillation counter.

Nitrite was analysed as a marker of NO concentration as proposed by Lauer et $a l^{(33)}$. Nitrite concentration in the serum was analysed with a commercially available nitrite/ nitrate assay: nitric oxide $\left(\mathrm{NO}_{2}^{-} / \mathrm{NO}_{3}^{-}\right)$assay kit obtained from R\&D Systems, Abingdon, UK. The principle for the colorimetric detection of nitrite is the Griess reaction. In short, diazonium ions are produced when acidified nitrite reacts with sulfanilic acid. These diazonium ions form chromophore agents when reacting with $N$-(1-naphthyl)ethylenediamine. Optical density was determined with a Spectramax reader at $540 \mathrm{~nm}$.

Genomic DNA was isolated from venous blood using QIAmp DNA Mini Kit (QIAGEN, Hilden, Germany). The $A C E$ gene contains a polymorphism based on the absence and/or presence of a $287 \mathrm{bp}$ non-sense DNA domain in intron 16, which results in three different genotypes: deletion/deletion homozygote $(D D)$, insertion/insertion homozygote (II) and insertion/deletion heterozygote (ID). Three primers, 5'-CTG CAG GTG TCT GCA GCA TGT GC-3', 5'-GAT TAC AGG CGT GAT ACA GTC ACT TTT-3' and 5'-GCC ATC ACA TTC GTC AGA TCT GGT AG-3' (Invitrogen Ltd, Paisley, UK), were used according to the method of Cheon et al. ${ }^{(34)}$.

For the PCR, a 'ready-to-use' reaction mixture (REDExtract-N-Amp Blood PCR ReadyMix; Sigma-Aldrich, St. Louis, MO, USA) was used in a total volume of $20 \mu \mathrm{l}$. Each primer was used at a concentration of $0.4 \mu \mathrm{m}$ and for each reaction $2 \mu \mathrm{l}$ DNA solution was added to the reaction mixture.

The PCR was performed in a Perkin Elmer Cetus DNA Thermal Cycler and started with 5 min of initial denaturation at $94^{\circ} \mathrm{C}$. Then the samples underwent thirty cycles of amplification: $45 \mathrm{~s}$ of denaturation $\left(94^{\circ} \mathrm{C}\right), 45 \mathrm{~s}$ of annealing $\left(65^{\circ} \mathrm{C}\right)$ and $45 \mathrm{~s}$ of extension $\left(72^{\circ} \mathrm{C}\right)$. The reaction was finished with $7 \mathrm{~min}$ of final extension $\left(72^{\circ} \mathrm{C}\right)$ and hold at $4^{\circ} \mathrm{C}$. The PCR products were separated by electrophoresis on a $2 \%$ agarose gel, then stained with ethidium bromide and visualized with UV light. The PCR products detected with the primers are one $237 \mathrm{bp}$ fragment for the deleted allele, and one 525 and one $155 \mathrm{bp}$ fragment for the inserted allele.

\section{Statistical analysis}

Results are presented as means with their standard error. One unit (U) of ACE activity is defined as the amount of the enzyme required to release $1 \mu$ mole hippuric acid per minute and litre. Graph Pad Prism 5.0 (La Jolla, CA, USA) was used for statistical calculations. One-way ANOVA for repeated measures was performed followed by Dunnett's post hoc test or Bonferroni's post hoc test (questionnaire). Statistical significance was taken at $P<0 \cdot 05$.

\section{Results}

\section{Angiotensin-converting enzyme activity}

After oral intake of $400 \mathrm{ml}$ green tea, black tea or Rooibos tea, significant inhibition of ACE activity was seen with the Rooibos tea after $30 \mathrm{~min}(P<0 \cdot 01)$ and after $60 \mathrm{~min}$ $(P<0 \cdot 05)$. No significant inhibition was seen with the green tea or the black tea (Figs $1 \mathrm{a}, \mathrm{b}$ and $\mathrm{c}$ ). When the participants were grouped according to $A C E$ genotype, a significant inhibition of ACE activity was seen with the green tea for the $I I$ genotype $30 \mathrm{~min}$ after intake of the tea (a)
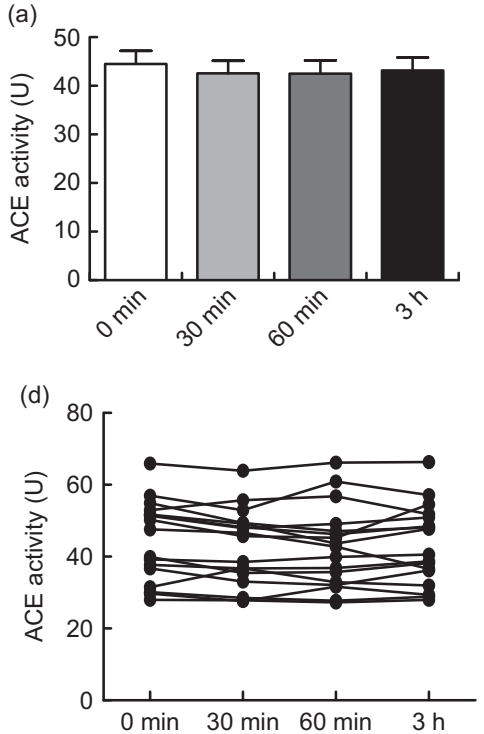

(b)

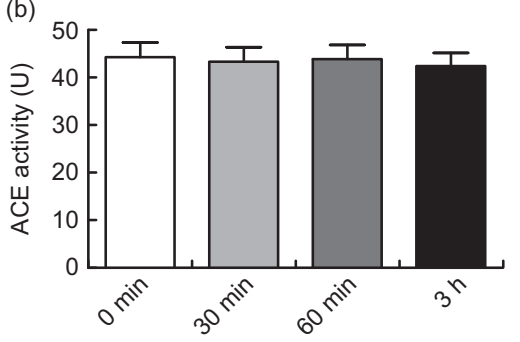

(e)

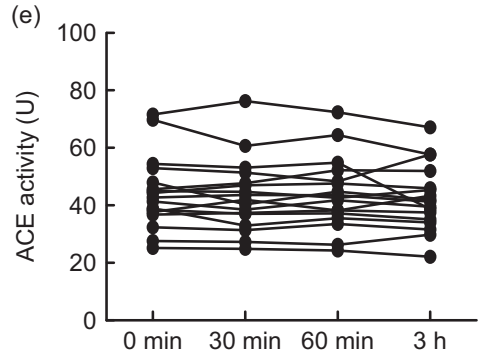

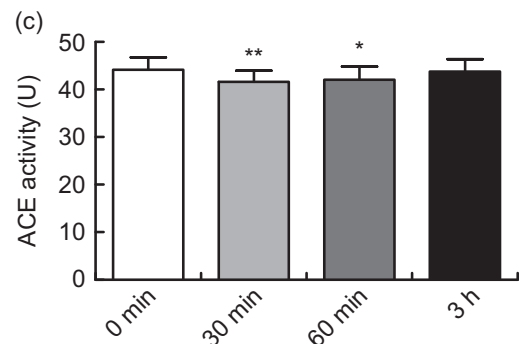

(f)

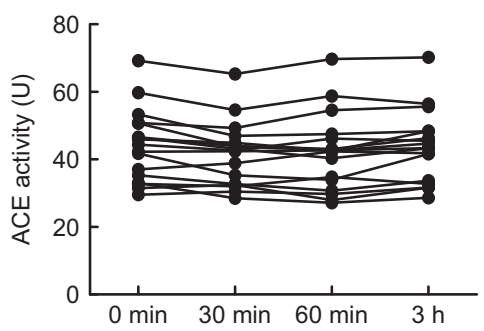

Fig. 1 Angiotensin-converting enzyme (ACE) activity in serum before oral intake and 30,60 min and $3 \mathrm{~h}$ after intake of $400 \mathrm{ml}$ green tea (a, d), black tea (b, e) or Rooibos tea (c, f) in healthy volunteers (mean age 26 years, range 20-31 years), Sweden. The upper row $(a, b, c)$ shows mean values with their standard errors represented by vertical bars; the lower row (d, e, f) shows values from each individual. Mean values were significantly different from those at baseline (one-way ANOVA for repeated measures, $n$ 17): ${ }^{\star} P<0.05,{ }^{* *} P<0.01$ 
(a)

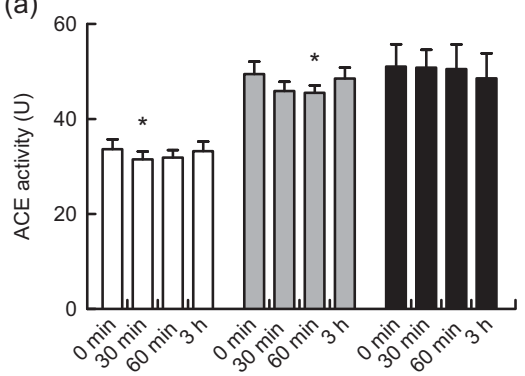

(b)

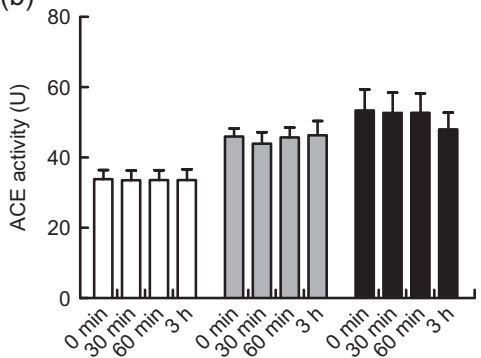

(c)

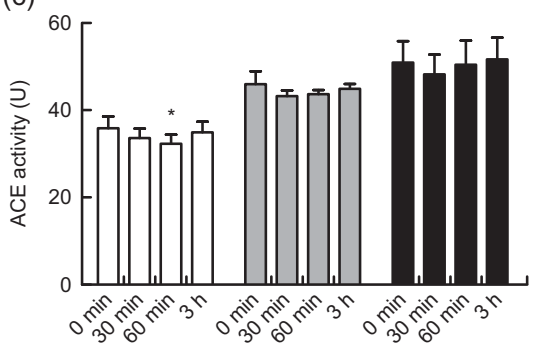

Fig. 2 Angiotensin-converting enzyme (ACE) activity in serum before oral intake and 30,60 min and $3 \mathrm{~h}$ after intake of $400 \mathrm{ml}$ green tea (a), black tea (b) or Rooibos tea (c) according to $A C E$ genotype $(I I, \square ; I D, \square ; D D, \square$ ) in seventeen healthy volunteers (mean age 26 years, range 20-31 years), Sweden. Values are means with their standard errors represented by vertical bars. Mean values were significantly different from those at baseline (one-way ANOVA for repeated measures; II, $n 6 ; I D, n 5 ; D D, n 6$ ): ${ }^{\star} P<0.05$

$(P<0 \cdot 05)$ and for the ID genotype $60 \mathrm{~min}$ after intake of the tea $(P<0 \cdot 05$; Fig. 2a). A significant inhibition of ACE activity was also seen with the Rooibos tea for the $I I$ genotype $60 \mathrm{~min}$ after intake of the tea $(P<0 \cdot 05$; Fig. 2c). No significant effect was seen with the black tea (Fig. 2b). No significant effect was seen with any of the teas for the $D D$ genotype (Figs 2a to c). The basal level of ACE activity was significantly higher $(P<0.001)$ for the participants with the $I D$ and $D D$ genotypes compared with those with the II genotype (Fig. 3). No difference was seen between males and females in any of the groups.

\section{Blood pressure and beart rate}

Basal blood pressure (supine, standing; mmHg) was 121 (SE 1·2)/71 (SE 1·1), $122(\operatorname{se~1\cdot 5)/74~(SE~1·1).~Blood~pressure~}$ (supine, standing; $\mathrm{mmHg}$ ) was 118 (SE 1.4)/71 (SE 1.1), 121 (SE 1.8)/74 (SE 1.3) after $30 \mathrm{~min} ; 117$ (SE 1.5)/72 (SE $1 \cdot 0), 120(\mathrm{se} 1 \cdot 8) / 75(\mathrm{se} 1 \cdot 3)$ after $60 \mathrm{~min}$; and $116(\mathrm{se} 1 \cdot 5) /$ 71 (SE 0.9), 119 (se 2.0)/74 (se 1.3) after 3 h. No significant change in blood pressure was seen after intake of any of the teas.

Basal heart rate (supine, standing; beats/min) was 75 (SE 2), 83 ( $\mathrm{se}$ 2). Heart rate (supine, standing; beats/min) was 65 (SE 2), 71 (sE 2) after $30 \mathrm{~min} ; 63$ (sE 2), 71 (sE 2) after $60 \mathrm{~min}$; and 60 (SE 2), 70 (SE 2) after 3 h. No significant change in heart rate was seen after intake of any of the teas.

\section{Nitric oxide concentration}

After oral intake of $400 \mathrm{ml}$ green tea, black tea or Rooibos tea, no significant effect on the NO concentration was seen (Fig. 4). After grouping the participants according to $A C E$ genotype $I I, I D$ or $D D$, no significant effect was seen on NO concentration (data not shown).

\section{The questionnaire}

Average daily intake of green tea, black tea, Rooibos tea, coffee, vegetables and fruits is shown in Table 1. A significant $(P<0 \cdot 01)$ difference was seen in intake of fruits and vegetables plus fruits between females and males (Table 1). The most consumed fruit were apples and bananas, and the most consumed vegetables were

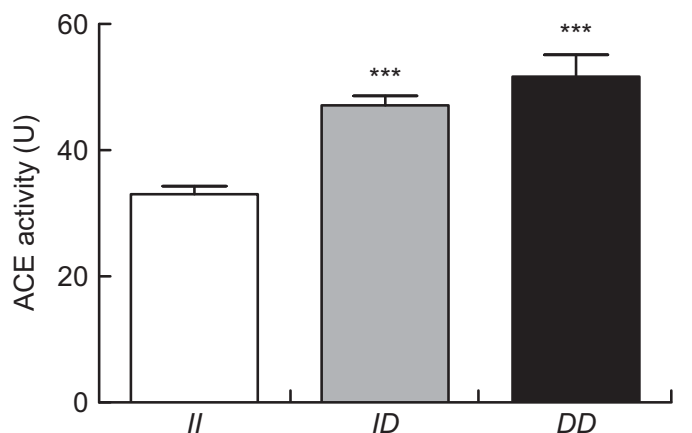

Fig. 3 Basal angiotensin-converting enzyme (ACE) activity in serum according to $A C E$ genotype in healthy volunteers (mean age 26 years, range $20-31$ years), Sweden. Values are means with their standard errors represented by vertical bars. Mean values were significantly different from those of the // genotype (one-way ANOVA; II, $n 6 ; I D, n 5 ; D D, n 6$ ): ${ }^{* \star} P<0 \cdot 001$

tomatoes. No differences in intake of apples, bananas and tomatoes were seen between males and females.

\section{Discussion}

The current in vivo study showed a significant inhibition of ACE activity at 30 and $60 \mathrm{~min}$ after oral intake of Rooibos tea, while green tea and black tea showed no significant inhibition of ACE activity for the total group of participants (Figs 1a, b and c).

It was previously shown that green tea and black tea significantly inhibit ACE activity in human endothelial cells in vitro while Rooibos tea did not inhibit ACE activity in vitro ${ }^{(11)}$. This discrepancy between the in vitro and in vivo studies may be due to either the content of the flavonoids or/and the metabolism of the components in the different teas, as there are differences in pharmacokinetics/metabolism between different flavonoids ${ }^{(35)}$. The discrepancy between the studies could also be due to the bioavailability or/and to a possible different mechanism of action of the Rooibos tea compared with the green tea and the black tea. 

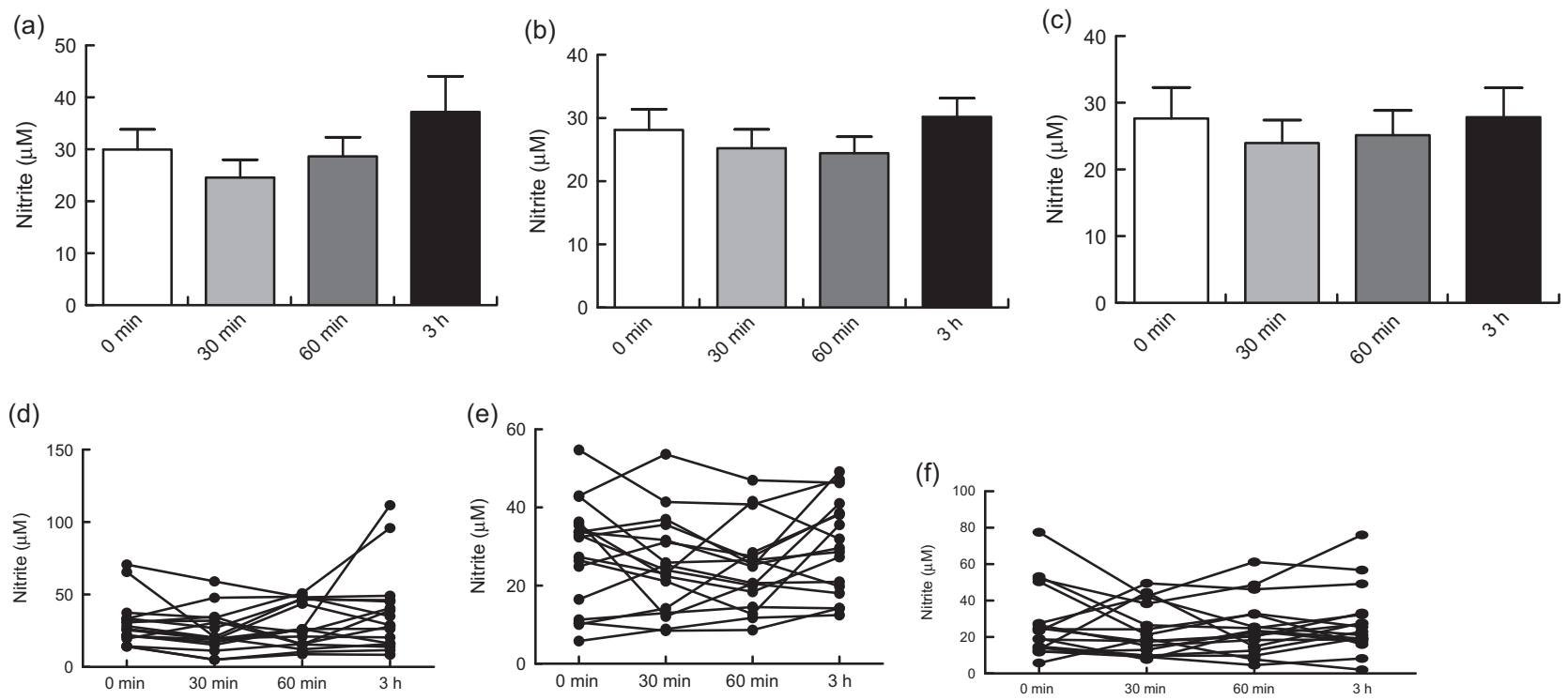

Fig. 4 Nitric oxide (NO) production (nitrite was analysed as a marker of NO concentration) in serum before oral intake and 30 , $60 \mathrm{~min}$ and $3 \mathrm{~h}$ after intake of green tea (a, d), black tea (b, e) or Rooibos tea (c, f) in healthy volunteers (mean age 26 years, range 20-31 years), Sweden. The upper row ( $a, b, c)$ shows mean values with their standard errors represented by vertical bars; the lower row (d, e, f) shows values from each individual. There were no significant differences in NO production compared with baseline (one-way ANOVA for repeated measures, $n$ 17)

Table 1 Participants' daily intake of flavonoid-containing foods from the questionnairet: seventeen healthy volunteers (mean age 26 years, range 20-31 years), Sweden

\begin{tabular}{|c|c|c|c|c|c|c|c|c|c|c|c|c|}
\hline & \multicolumn{2}{|c|}{ Total $(n 17)$} & \multicolumn{2}{|c|}{ Male $(n 9)$} & \multicolumn{2}{|c|}{ Female $(n 8)$} & \multicolumn{2}{|c|}{ // genotype $(n 6)$} & \multicolumn{2}{|c|}{ ID genotype $(n 5)$} & \multicolumn{2}{|c|}{$D D$ genotype $(n 6)$} \\
\hline & Mean & Min, max & Mean & Min, max & Mean & Min, max & Mean & Min, max & Mean & Min, max & Mean & Min, max \\
\hline Green tea & $0 \cdot 12$ & $0,0.57$ & 0.09 & $0,0.43$ & $0 \cdot 13$ & $0,0.57$ & $0 \cdot 20$ & $0,0.57$ & $0 \cdot 11$ & $0,0.43$ & 0.00 & - \\
\hline Black tea & 0.33 & 0,2 & $0 \cdot 16$ & $0,0.57$ & $0 \cdot 49$ & 0,2 & 0.08 & $0,0 \cdot 28$ & 0.60 & 0,2 & 0.30 & $0,0 \cdot 71$ \\
\hline Rooibos tea & $0 \cdot 15$ & 0,1 & $0 \cdot 13$ & 0,1 & $0 \cdot 18$ & 0,1 & $0 \cdot 27$ & $0,0.96$ & 0.23 & 0,1 & 0.01 & $0,0.07$ \\
\hline Coffee & 0.89 & 0,4 & 0.92 & 0,4 & $0 \cdot 87$ & 0,4 & $1 \cdot 26$ & 0,4 & $0 \cdot 26$ & $0,1 \cdot 28$ & $0 \cdot 76$ & 0,4 \\
\hline Vegetables & $1 \cdot 36$ & $0.57,2$ & $1 \cdot 31$ & $0.57,2$ & $1 \cdot 40$ & $0.57,2$ & $1 \cdot 60$ & $0 \cdot 86,2$ & $1 \cdot 51$ & $0 \cdot 71,2$ & $1 \cdot 19$ & $0.57,2$ \\
\hline Fruits & $1 \cdot 80$ & $0 \cdot 28,4$ & 0.95 & $0.57,2$ & $2 \cdot 50^{* *}$ & $0 \cdot 71,4$ & $1 \cdot 40$ & $0 \cdot 28,3$ & $1 \cdot 71$ & $0 \cdot 28,4$ & $2 \cdot 21$ & $0.57,4$ \\
\hline Vegetables and fruits & $3 \cdot 16$ & $1 \cdot 14,6$ & $2 \cdot 26$ & $1 \cdot 14,4$ & $3 \cdot 97^{\star *}$ & $1 \cdot 28,6$ & $3 \cdot 00$ & $1 \cdot 57,5$ & $3 \cdot 23$ & $1 \cdot 28,6$ & $3 \cdot 40$ & $1 \cdot 14,6$ \\
\hline
\end{tabular}

Min, minimum; max, maximum.

tIntake based on answers to the following questions: (i) 'How many cups of tea do you drink per day?' ( 1 cup of tea is $250 \mathrm{ml}$ ); (ii) 'How many cups of coffee do you drink per day?' ( 1 cup of coffee is $150 \mathrm{ml}$ ); (iii) 'How many times per day do you eat vegetables?'; and (iv) 'How many times per day do you eat fruit?' Mean values were significantly different from those of males: ${ }^{\star \star} P<0.01$.

The I/D polymorphism of the $A C E$ gene is proposed to be important concerning serum levels of $\mathrm{ACE}^{(22,23)}$. As shown in Fig. 3, basal ACE activity of the participants showed a significant difference between the ACE II genotype and the $I D$ and $D D$ genotypes in accordance with the results of Rigat et al. ${ }^{(22)}$. The $D$ allele of the $A C E$ gene was previously proposed to be correlated with $\mathrm{CVD}^{(26,36)}$. According to Fig. 2, the ACE II and ID genotypes seem to be more sensitive to ACE inhibition by the different teas than the $D D$ genotype. A significant inhibition of ACE activity was seen for the $I I$ and $I D$ genotypes with green tea and for the II genotype with Rooibos tea. The same pattern in ACE inhibitory action depending on ACE genotype has previously been shown with glyceryl trinitrate $^{(37)}$. Hence, it seems that the $D D$ genotype could be a risk factor for CVD, as previously proposed ${ }^{(24)}$. The difference between genotypes may also be a question of dosage. ID and even more the $D D$ genotype might need higher amounts of flavonoids to affect ACE activity than the II genotype ${ }^{(38)}$.

The effects of green and black tea on CVD are suggested to be due to their high content of catechins, i.e. epicatechin, epigallocatechin, epicatechingallate and epigallocatechingallate ${ }^{(11)}$, while Rooibos tea does not contain any catechins ${ }^{(11)}$ but dihydrochalcones, flavones and flavonols ${ }^{(12)}$. The catechins especially epigallocatechingallate showed strong inhibitory effects on ACE activity in vitro ${ }^{(11)}$. The slight inhibition of ACE activity seen by Rooibos tea in vitro might depend on its quercetin (flavonol) content, since quercetin exhibits an ACE 
inhibitory action in vitro ${ }^{(39)}$. The two active sites of ACE contain $\mathrm{Zn}^{2+}$, and ability to bind the $\mathrm{Zn}^{2+}$ ion will inhibit ACE activity ${ }^{(40)}$. ACE inhibition leads to less angiotensin $\mathrm{II}$, and an increase of NO leads to down-regulation of $\mathrm{AT}_{1}$ receptors. Our previous in vitro study showed an increased NO concentration by green tea, black tea and Rooibos tea ${ }^{(11)}$, but the current in vivo study did not show any significant effect on NO concentration after oral intake of any of the teas (Figs $4 \mathrm{a}, \mathrm{b}$ and c). A possible explanation may be that we determined nitrite as a marker of NO, and nitrite is also a product of protein metabolism. As shown in Figs $1 \mathrm{~d}$ to $\mathrm{f}$ and Figs $4 \mathrm{~d}$ to $\mathrm{f}$, the participants exhibited substantial individual variations in ACE activity as well as NO concentration and this fact may also influence the results. It must be taken into consideration that our in vivo study examined the effect on ACE activity and NO concentration after a single dose (one cup) of tea. The average inhibition of ACE activity $30 \mathrm{~min}$ after intake of Rooibos tea was 6\%, compared with $16 \%$ inhibition of ACE activity after chronic intake of enalapril $10 \mathrm{mg}^{(41)}$. In the current study, no effect on blood pressure was seen after intake of tea. Since the RAAS is involved in long-term regulation of homeostasis, such an effect could not be expected. One previous study with 1 week's intake of black tea showed a significant reduction in blood pressure and increase in flow-mediated vasodilation in healthy volunteers ${ }^{(42)}$. However, in a metaanalysis including the cardiovascular effects of black and green tea, no reduction in blood pressure was seen ${ }^{(43)}$. None of these studies included ACE activity among the investigated parameters. Further studies investigating regular long-term intake of tea remain to be performed.

Diet is of great importance to human health ${ }^{(44-47)}$. The prevention of CVD is attributed to a diversity of effects such as antioxidative ${ }^{(48)}$, antithrombotic and anti-inflammatory properties, activation of endothelial nitric oxide synthase and inhibition of LDL oxidation ${ }^{(49-53)}$. Flavonoids, e.g. catechins found in green tea and black tea and flavonols found in Rooibos tea, are plant-derived antioxidants with alleged positive effect on the cardiovascular system $^{(49,54)}$. However, the positive effect of fruit, vegetables and tea on CVD cannot always be solely explained by their antioxidative action. The present study shows an additional mechanism, flavonoids as ACE inhibitors.

The average intake of vegetables and fruit by the participants was approximately three times daily (Table 1). A significant difference was seen in frequency of intake of fruits and thereby in intake of vegetables plus fruits between females and males. Thus, according to this questionnaire, females consumed significantly more fruits than males. Recommendation from the Swedish National Food Administration is five times daily (or $500 \mathrm{~g} / \mathrm{d}$ ) for fruits and vegetables. According to the questionnaire, the most consumed fruits are apple and banana, and the most consumed vegetable is tomato. Apples, bananas and tomatoes also contain flavonoids, but at a much lower content than tea. Flavonoids, e.g. catechins found in tea, vegetables and fruits, are well known for their protective effect against CVD. Considering that, the intake of flavonoids among the subjects of the experiment seems to be generally low. Average daily intake of flavonoids is difficult to assess, it depends on season, availability, soil, climate and dietary habits.

\section{Conclusion}

In conclusion, oral intake of a single dose $(400 \mathrm{ml})$ of Rooibos tea significantly inhibited ACE activity in healthy volunteers. When the participants were divided into subgroups according to $A C E$ genotype, those with genotypes $I I$ and $I D$ showed a significant inhibition of ACE activity after intake of green tea and Rooibos tea, while participants with $A C E$ genotype $D D$ seemed to be more difficult to affect with a single dose of tea. ACE inhibitors are the first-line treatment of hypertension and thus a common drug used for CVD. Intake of high amounts of flavonoids, i.e. tea, vegetables and fruits, might contribute to the prevention of CVD in the population and thereby prevent CVD mortality. These results suggest that green tea and Rooibos tea may have cardiovascular effects through inhibition of ACE activity. Additional experimental and clinical studies are needed in order to further elucidate these effects.

\section{Acknowledgements}

The study was supported by grants from Östergötlands County Council (LIO-8355) and the Cardiovascular Inflammation Research Centre (CIRC) at Linköping University. None of the authors have conflicts of interest. All the authors contributed to the design of the study. I.A.-L.P. performed the study, the analysis, interpreting the data and drafting the manuscript. S.H. was the physician responsible for the collection of blood samples. K.P. and R.G.G.A. conducted data analysis and interpretation. All of the authors read and approved the final manuscript. The authors acknowledge Marja Tjädermo and Ingela Jacobsson for excellent technical and clinical assistance.

\section{References}

1. Balentine DA, Wiseman SA \& Bouwens LCM (1997) The chemistry of tea flavonoids. Crit Rev Food Sci Nutr 37, 693-704.

2. Hakim IA, Alsaif MA, Alduwaihy M et al. (2003) Tea consumption and the prevalence of coronary heart disease in Saudi adults: results from a Saudi national study. Prev Med 36, 64-70.

3. Mukamal KJ, Maclure M, Muller JE et al. (2002) Tea consumption and mortality after acute myocardial infarction. Circulation 105, 2476-2481.

4. Basu A \& Lucas EA (2007) Mechanisms and effects of green tea on cardiovascular health. Nutr Rev 65, 361-375. 
5. Inami S, Takano M, Yamamoto M et al. (2008) Tea catechin consumption reduces circulating oxidized low-density lipoprotein. Int Heart J 48, 725-732.

6. O'Keefe JH, Gheewala NM \& O'Keefe J (2008) Dietary strategies for improving post-prandial glucose, lipids, inflammation, and cardiovascular health. J Am Coll Cardiol 51, 249-255.

7. Tipoe GL, Leung TM, Hung MW et al. (2007) Green tea polyphenols as an anti-oxidant and anti-inflammatory agent for cardiovascular protection. Cardiovasc Hematol Disord Drug Targets 7, 135-144.

8. Kim SK, Kim HJ, Choi SE et al. (2008) Anti-oxidative and inhibitory activities on nitric oxide (NO) and prostaglandin $\mathrm{E}_{2}$ (COX-2) production of flavonoids from seeds of Prunus tomentosa Thunberg. Arch Pharm Res 31, 424-428.

9. Ahmed S, Rahman A, Hasnain A et al. (2002) Green tea polyphenol epigallocatechin-3-gallate inhibits the IL-1 $\beta$ induced activity and expression of cyclooxygenase- 2 and nitric oxide synthase-2 in human chondrocytes. Free Radic Biol Med 33, 1097-1105.

10. Miura Y, Chiba T, Tomita L et al. (2001) Tea catechins prevent the development of atherosclerosis in apoprotein e-deficient mice. J Nutr 131, 27-32.

11. Persson IA-L, Josefsson M, Persson K et al. (2006) Tea flavanols inhibit angiotensin-converting enzyme activity and increase nitric oxide production in human endothelial cells. J Pharm Pharmacol 58, 1139-1144.

12. Bramati L, Aquiland F \& Pietta P (2003) Unfermented Rooibos tea. Quantitative characterization of flavonoids by HPLC-UV and determination of the total antioxidant activity. J Agric Food Chem 51, 7472-7474.

13. Nishimura H (2000) Angiotensin receptors - evolutionary overview and perspectives. Comp Biochem Physiol 128, 11-30.

14. Benson SC, Iguchi R, Ho CI et al. (2008) Inhibition of cardiovascular cell proliferation by angiotensin receptor blockers: are all molecules the same? J Hypertens 26, 973-980.

15. Fogari R \& Zoppi A (2006) Antihypertensive drugs and fibrinolytic function. Am J Hypertens 19, 1293-1299.

16. Rush JW \& Aultman CD (2008) Vascular biology of angiotensin and the impact of physical activity. Appl Physiol Nutr Metab 33, 162-172.

17. Weiss D, Sorescu D \& Taylor WR (2001) Angiotensin II and atherosclerosis. Am J Cardiol 87, 25C-32C.

18. Birkenhäger WH \& Staessen JA (2006) Progress in cardiovascular diseases: cognitive function in essential hypertension. Prog Cardiovasc Dis 49, 1-10.

19. Gard PR (2002) The role of angiotensin II in cognition and behavior. Eur J Pharmacol 438, 1-14.

20. McGuiness B, Todd S, Passmore P et al. (2006) Blood pressure lowering in patients without prior cerebrovascular disease for comparative pharmacological interruption of the renin system. Hypertension 32, 387-392.

21. Reed R, Kolz C, Potter B et al. (2008) The mechanistic basis for the disparate effects of angiotensin II on coronary collateral growth. Arterioscler Thromb Vasc Biol 28, 61-67.

22. Rigat B, Hubert C, Alhenc-Gelas F et al. (1990) An insertion/deletion polymorphism in the angiotensin Iconverting enzyme gene accounting for half the variance of serum enzyme levels. J Clin Invest 86, 1343-1346.

23. Tiret L, Rigat B, Visvikis S et al. (1992) Evidence, from combined segregation and linkage analysis, that a variant of the angiotensin I-converting enzyme (ACE) gene controls plasma ACE levels. Am J Hum Genet 51, 197-205.

24. Beohar N, Damaraju S, Prather A et al. (1995) Angiotensin-I converting enzyme genotype $\mathrm{DD}$ is a risk factor for coronary artery disease. J Investig Med 43, 275-280.

25. Cambien F, Poirier O, Lecerf L et al. (1992) Deletion polymorphism in the gene for angiotensin-converting enzyme is a potent risk factor for myocardial infarction. Nature 359, 641-644.
26. Samani NJ, Thompson JR, O’Toole L et al. (1996) A metaanalysis of the association of the deletion allele of the angiotensin-converting enzyme gene with myocardial infarction. Circulation 94, 708-712.

27. Millatt LJ, Abdel-Rahman EM \& Siragy HM (1999) Angiotensin II and nitric oxide: a question of balance. Regul Pept 81, $1-10$.

28. Fernándes-Alfonso MS \& González C (1999) Nitric oxide and the renin-angiotensin system. Is there a physiological interplay between the systems? J Hypertens 17, 1355-1361.

29. Kurz S, Hink U, Nickenig G et al. (1999) Evidence for a causal role of the renin-angiotensin system in nitrate tolerance. Circulation 99, 3181-3187.

30. Ackermann A, Fernández-Alfonso MS, Sánchez de Rojas R et al. (1998) Modulation of angiotensin-converting enzyme by nitric oxide. BrJ Pharmacol 124, 291-298.

31. Persson K \& Andersson RGG (1999) Nitric oxide modulates captopril-mediated angiotensin-converting enzyme inhibition in porcine iliac arteries. Eur J Pharmacol 385, 21-27.

32. Persson K, Whiss PW, Nyhlén K et al. (2000) Nitric oxide donors and angiotensin-converting enzyme inhibitors act in concert to inhibit human angiotensin-converting enzyme activity and platelet aggregation in vitro. Eur J Pharmacol 406, 15-23.

33. Lauer T, Preik M, Rassaf T et al. (2001) Plasma nitrite rather than nitrate reflects regional endothelial nitric oxide synthase activity but lacks intrinsic vasodilator action. Proc Natl Acad Sci USA 98, 12814-12819.

34. Cheon KT, Choi KH, Lee HB et al. (2000) Gene polymorphisms of endothelial nitric oxide synthase and angiotensin-converting enzyme in patients with lung cancer. Lung 178, 351-360.

35. Karakaya S (2004) Bioavailability of phenolic compounds. Crit Rev Food Sci Nutr 44, 453-464.

36. Cambien F (1994) The angiotensin-converting enzyme (ACE) genetic polymorphism: its relationship with plasma ACE level and myocardial infarction. Clin Genet 46, 94-101.

37. Persson K, Säfholm ACE, Andersson RGG et al. (2005) Glyceryl trinitrate-induced angiotensin-converting enzyme (ACE) inhibition in healthy volunteers is dependent on ACE genotype. Can J Physiol Pharmacol 83, 1117-1122.

38. Danser AHJ, Batenburg WW, van den Meiracker AH et al. (2007) ACE phenotyping as a first step toward personalized medicine for ACE inhibitors. Why does ACE genotyping not predict the therapeutic efficacy of ACE inhibitors? Pharmacol Ther 113, 607-618.

39. Persson IA-L, Lindén E, Andersson M et al. (2008) Effects of Ginkgo biloba extract EGb 761 and its terpene-lactones on angiotensin converting enzyme activity and nitric oxide production in human endothelial cells. Asian J Trad Med $\mathbf{3}$, $42-51$.

40. Berecek K \& Zhang L (1995) Biochemistry and cell biology of angiotensin-converting enzyme and converting enzyme inhibitors. Adv Exp Med Biol 377, 141-168.

41. Abrams WB, Davies RO \& Gomez HJ (1984) Clinical pharmacology of enalapril. J Hypertens Suppl 2, 31-36.

42. Grassi D, Mulder TPJ, Draijer R et al. (2009) Black tea consumption dose-dependently improves flow-mediated dilation in healthy males. J Hypertens 27, 774-781.

43. Hooper L, Kroon PA, Rimm EB et al. (2008) Flavonoids, flavonoid-rich foods, and cardiovascular risk: a metaanalysis of randomized controlled trials. Am J Clin Nutr $\mathbf{8 8}, 38-50$.

44. Allen RR, Carson L, Kwik-Uribe C et al. (2008) Daily consumption of a dark chocolate containing flavanols and added sterol esters affect cardiovascular risk factors in a normotensive population with elevated cholesterol. J Nutr 138, 725-731.

45. Chen CM, Zhao W, Yang Z et al. (2008) The role of dietary factors in chronic disease control in China. Obes Rev $\mathbf{9}$, Suppl. 1, 100-103. 
46. López EP, Rice C, Weddle DO et al. (2008) The relationship among cardiovascular risk factors, diet patterns, alcohol consumption, and ethnicity among women aged 50 years and older. J Am Diet Assoc 108, 248-256.

47. Patterson C, Feightner JW, Garcia A et al. (2008) Diagnosis and treatment of dementia: risk assessment and primary prevention of Alzheimer disease. CMAJ 178, 548-556.

48. Dragsted LO (2003) Antioxidant actions of polyphenols in humans. Int J Vitam Nutr Res 73, 112-119.

49. Aron PM \& Kennedy JA (2008) Flavan-3-ols: nature, occurrence and biological activity. Mol Nutr Food Res 52, 79-104

50. Boots AW, Haenen GRMM \& Bast A (2008) Health effects of quercetin: from antioxidant to nutraceutical. Eur J Pharmacol 585, 325-337.
51. Hwang J, Wang J, Morazzoni P et al. (2003) The phytoestrogen equol increases nitric oxide availability by inhibiting superoxide production: an antioxidant mechanism for cell-mediated LDL modification. Free Radic Biol Med 34, 1271-1282.

52. Ikizler M, Erkasap N, Dernek S et al. (2007) Dietary polyphenol quercetin protects rat hearts during reperfusion: enhanced antioxidant capacity with chronic treatment. Anatolian J Cardiol 7, 404-410.

53. Kaliora AC \& Dedoussis GVZ (2007) Natural antioxidant compounds in risk factors for CVD. Pharmacol Res 56, 99-109.

54. Svarcova I, Heinrich J \& Valentova K (2007) Berry fruits as a source of biologically active compounds: the case of Lonicera caerulea. Biomed Pap Med Fac Univ Palacky Olomouc Czech Repub 151, 163-174. 